\title{
Melano-macrophage centres in liver and spleen of ruffe (Gymnocephalus cernua) from the Elbe Estuary
}

\author{
H. Kranz \& N. Peters \\ Zoologisches Institut und Zoologisches Museum, Universität Hamburg; \\ Martin-Luther-King-Platz 3, D-2000 Hamburg 13, \\ Federal Republic of Germany
}

\begin{abstract}
Macrophages with yellow or black deposits of melanin occur singly or in groups in the melano-macrophage centres are functionally the primitive analogues of lymph nodes in birds and mammals. From 1980 to 1982, tumours and pretumorous tissue changes in ruffe from the Elbe Estuary were studied. Pathological alterations occur mainly in the liver and spleen. In connection with both, neoplastic abnormalities in liver and spleen, and fatty degenerative processes in the liver, an obvious increase in number and size of the melano-macrophage centres was observed. The colour, structure and some histochemical properties of melano-macrophage centres in the liver differ somewhat from those in the spleen. The majority of splenic centres were filled with large amounts of haemosiderin, whereas many hepatic macrophages contained fatty inclusions. Possible differences in the functions of splenic and hepatic melano-macrophage centres are discussed.
\end{abstract}

\section{INTRODUCTION}

Since fish do not have bone marrow or lymph nodes, the main sites of haemopoesis are the anterior kidney and the spleen. Less important for the production of blood cells in teleosts are special areas in the liver, the submucosa of the intestine, and the thymus (Roberts, 1978).

A characteristic feature of haemopoetic tissue is the presence of so-called melanomacrophage centres. These are nodules of macrophage cells which are more or less coloured by yellow, brown or black pigments, which are referred to as melanin. Melanin is a class of insoluble polycyclic polymers defined to include not only the pigments in melanophores but also related substances, such as lipofuscin and ceroids (Edelstein, 1971). In contrast to melanocytes, melano-macrophages are not able to synthesize melanin pigments, so the origin of this material must still be determined (Ellis, 1974). Groups of pigmented macrophages in the haemopoetic tissue of teleosts are often surrounded by a collar of lymphocytes, and some of the melano-macrophages contain immunoglobulins on their surface (Ellis, 1980). Because of these characteristics, it is assumed that melano-macrophage centres are the primitive analogues of the lymph nodes in higher vertebrates. The special function of these melano-macrophages is phagocytic consumption of catabolic products and foreign material, including injected carbon particles (Ellis et al., 1976). Therefore melano-macrophage centres can be considered as metabolic dumps (Agius, 1980).

From 1980 to 1982 , an investigation was carried out to study tumorous conditions in 
the ruffe Gymnocephalus cernua L, a percid fish, from the polluted Elbe Estuary (FRG). During this study, it became increasingly obvious that melano-macrophage centres in the spleen and liver augmented during the development of several histopathological abnormalities of these organs. It is the purpose of this paper to report preliminary observations on occurrence rates and special histological and histochemical characteristics of melano-macrophage centres in pathologically altered liver and spleen of the ruffe and to discuss possible differences in the function of melano-macrophages in both organs.

\section{MATERIAL AND METHODS}

A total of 551 ruffe from the Elbe Estuary between Hamburg Harbour and its mouth were examined for gross abnormalities of the liver and spleen. The size of the ruffe specimens taken ranged from 10 to $28 \mathrm{~cm}$. Animals were killed in MS $222(1 \mathrm{~g} / \mathrm{l})$ and dissected. The liver and spleen were removed, and the macroscopic appearance of each was noted. The organs were fixed in $6 \%$ buffered formalin or Bouin's solution. Subsamples selected for semi-thin Epon sections were fixed in $6 \%$ phosphate buffered glutaraldehyde. Some liver specimens taken to determine the presence of glycogen and fats were either fixed in Carnoy's fluid or deep frozen for cryostatic sectioning. Epon sections $1 \mu \mathrm{m}$ thick were stained with toluidine blue. Samples embedded in paraffin blocks were cut into $5 \mu \mathrm{m}$ sections, which were stained as follows: hematoxylin/eosin as general stains; azan for identification of connective tissue elements; Prussian blue for the demonstration of ferric iron; and Best's carmine with Kernechtrot to determine the glycogen content. Sudan black was used to detect fats in the $10 \mu \mathrm{m}$ cryostat sections (Romeis, 1948).

Samples of liver and/or spleen taken from a total of 77 fishes with apparently healthy organs and displaying various gross lesions were histologically examined. From 35 fishes, melano-macrophage centres of both the liver and spleen were microscopically analysed for direct comparison.

\section{RESULTS}

Ruffe from the polluted Elbe Estuary displayed three types of abnormalities which were remarkable because of their high incidence rates. The most frequent one is the only non-tumorous condition. It occurs in the liver. In $39 \%$ of the ruffe, livers display pale spots or marbled patterns on the surface, which were histochemically shown to be regions containing accumulations of lipoid compounds (Fig. 1). Areas with excessive fat storage were usually arranged around afferent blood vessels. Liver parenchyma sur-

Fig. 1. Liver tissue with limited region of fatty vacuolation in hepatocytes (paraffin $5.0 \mu \mathrm{m}$; hematoxylin-eosin; $\times 270$ )

Fig. 2. Hepatic melano-macrophage centre with homogeneous, vesicular structure of phagocytic vacuoles (paraffin $5.0 \mu \mathrm{m}$; hematoxylin; $\times 680$ )

Fig. 3. Initial stage of tumorous growth with megalocytic hepatocytes (paraffin $5.0 \mu \mathrm{m}$; hematoxylineosin; $\times 270$ )

Fig. 4. Border of neoplastic liver nodule. Melano-macrophage centres in the surrounding tissue, which is forced aside, are indicated by arrows (paraffin $5.0 \mu \mathrm{m}$; hematoxylin-eosin; $\times 195$ ) 


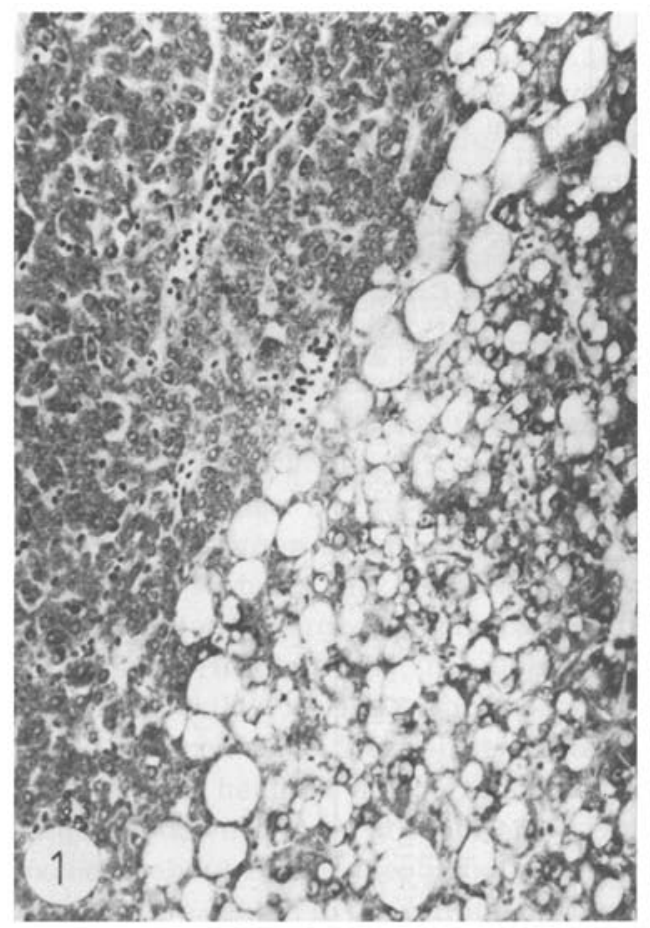

"49y. OHa P.

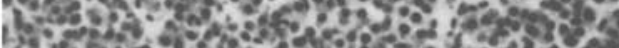

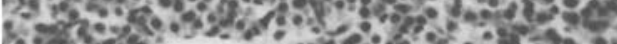
1. ova

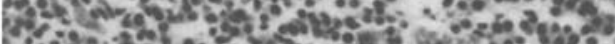

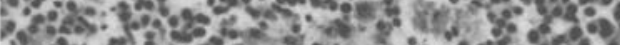

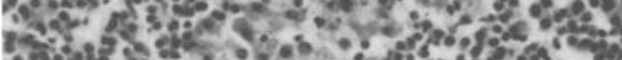
Lif

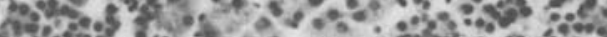

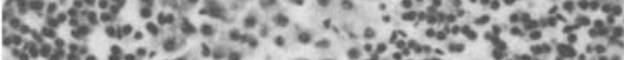

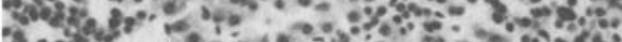

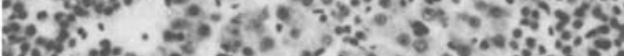

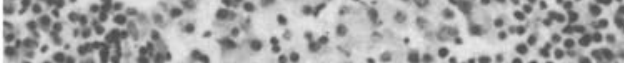

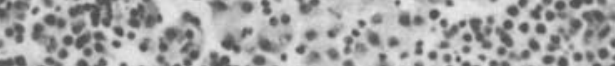

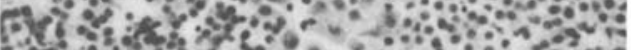

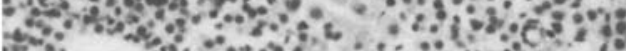
1.

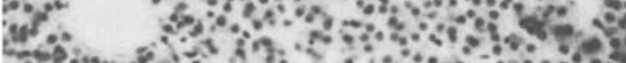

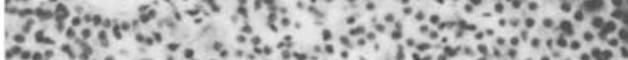

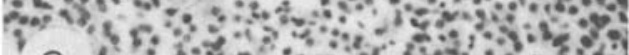
- 3 k

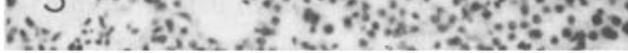
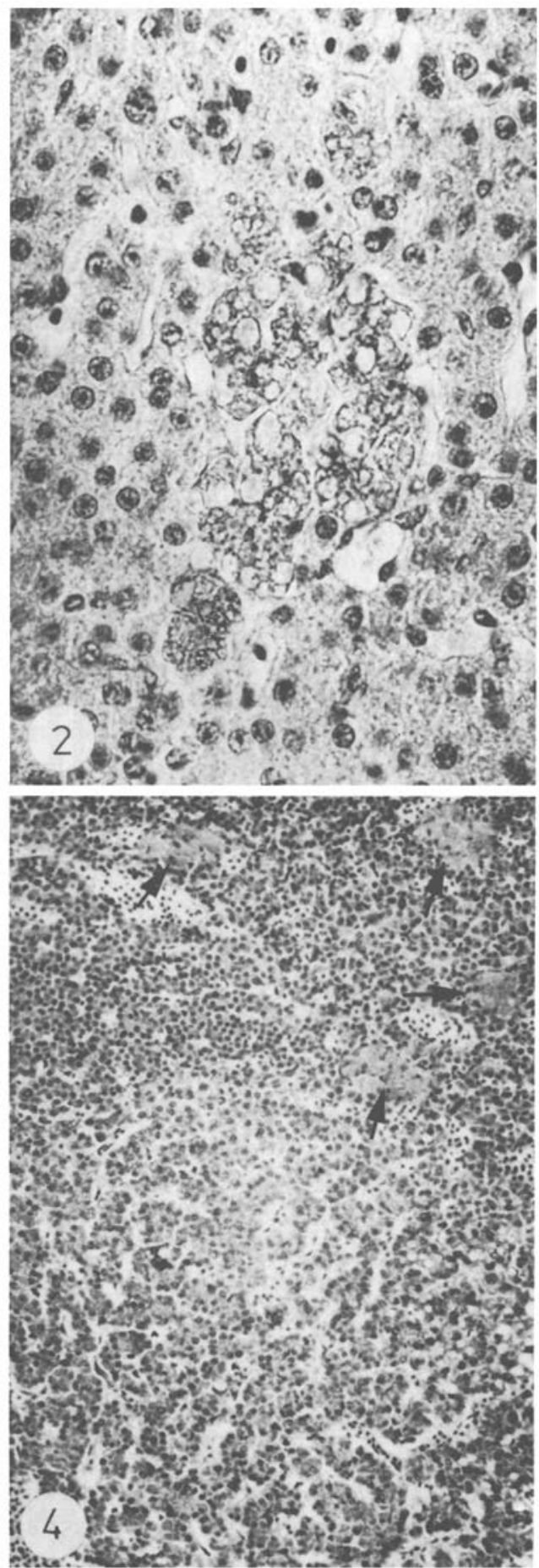


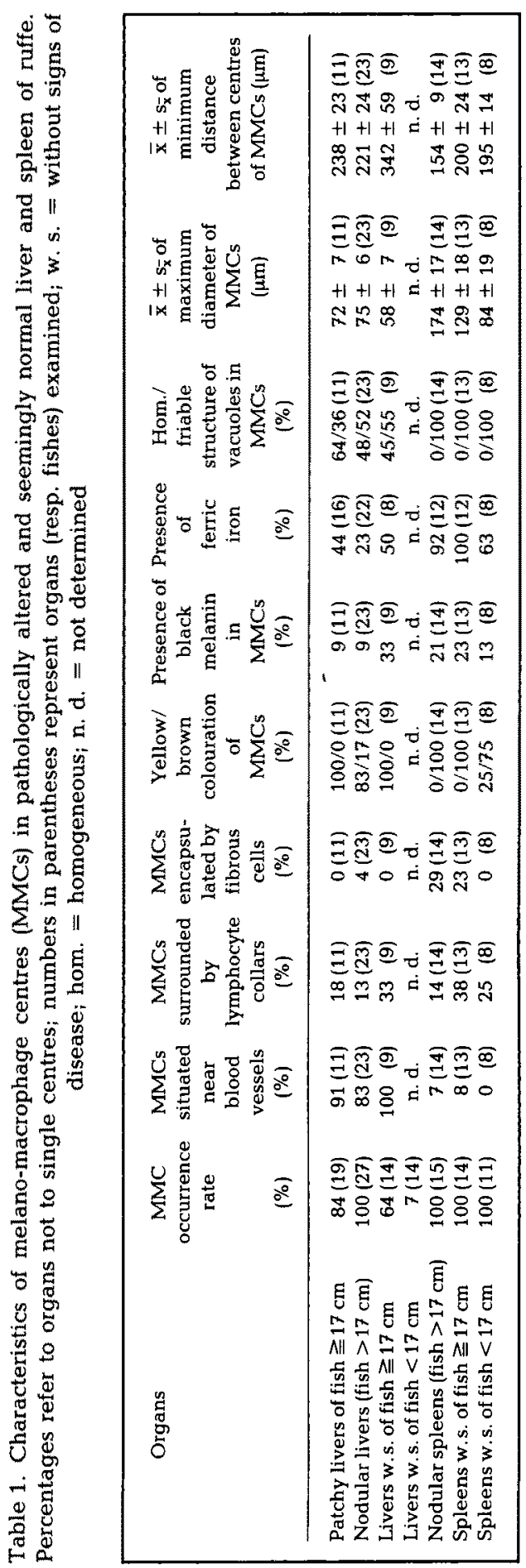


rounding these regions often showed slight signs of degeneration, such as dissociation of the lobular structure, vascular congestion, and sometimes also slightly necrotic processes. Somewhat limited areas of cells filled with fatty substances were often surrounded by increased numbers of enlarged melano-macrophage centres (Table 1). The colour of the melanin was light yellow in all cases, and inclusions of black melanin seldom occurred (Fig. 2). The structure of the macrophage phagocytic vacuoles in the majority of patchy livers was vesicular or homogeneous. Histochemical investigations revealed that lipoids played the same histological role as in the hepatocytes. Ferric iron was only demonstrated to occur in melano-macrophage centres of less than half of these livers. The reaction to detect it was weak, and it never accumulated in vacuoles but remained in the cytoplasm or surrounded the outside of the macrophages.

A second pathological condition in the liver of the ruffe is the development of tumorous nodules. During their initial stage, they could be diagnosed as pale glassy spots on the organ surface that develop into wart-like structures, sometimes with a papilliform surface. This disease, which occurred in $8 \%$ of the entire ruffe population, was restricted to larger specimens which had lived in contaminated water for at least four years. Histologically, the liver nodules develop from small groups of enlarged basophilic cells (Fig. 3). During process of advanced proliferation, the surrounding liver tissue is forced aside. The cell structure within the nodule gives the impression of being uniform and healthy, but the nucleus to cytoplasm ratios are slightly increased, and larger blood vessels are absent from the interior. When the diameter of the growth region exceeds about $5 \mathrm{~mm}$, the blood supply becomes insufficient, and necrotic processes begin in the centre. In the vicinity of these neoplastic liver nodules, melano-macrophage centres were always found to have increased in number and size (Fig. 4). The colour of the melanin was usually light yellow (Table 1), but in some cases, brown pigmented macrophages also occurred. Simultaneously, the percentage of livers with vesicular or homogeneous phagosomes in the centres decreased. In comparison to patchy livers resulting from fat accumulation, the abundance of organs with iron storage was decreased.

The third pathological condition affects the spleen. In $10 \%$ of the ruffe from the Elbe Estuary, opalescent or whitish spots and even protruding warts could be identified on the normally dark red organ. Just as in the case of the liver nodules, these splenic nodes were restricted to fishes in higher length classes (Table 2). As long as the spots are still relatively small, several of them can occur in the same organ. Individual spots enlarge and merge into each other. Histologically, these splenic nodules proved to be immensely proliferated fibrous capsules of capillaries, which in healthy spleen form the areas called ellipsoids (Fig. 5). If this proliferated tissue, the origin of which belongs to the reticuloendothelial system, might still be classified as vascular epithelium, the tumorous condition can be called an angioma. Using the light microscope, no phagocytosed substances could be observed in the proliferated ellipsoid cells. In the vicinity of the

Tahle 2. Relationship betwen splenic nodules and fish length

\begin{tabular}{|lrrrrrrrrrrrrrrrr|}
\hline Fish length (cm) & 10 & 11 & 12 & 13 & 14 & 15 & 16 & 17 & 18 & 19 & 20 & 21 & 22 & 23 & $>23$ \\
Frequency of nodules (\%) & 0 & 0 & 0 & 0 & 0 & 0 & 0 & 3.2 & 14.3 & 8.9 & 12.5 & 25.3 & 20.5 & 8.3 & 0 \\
Number of fish examined & 5 & 3 & 23 & 29 & 50 & 46 & 28 & 31 & 35 & 56 & 96 & 91 & 44 & 12 & 2 \\
\hline
\end{tabular}




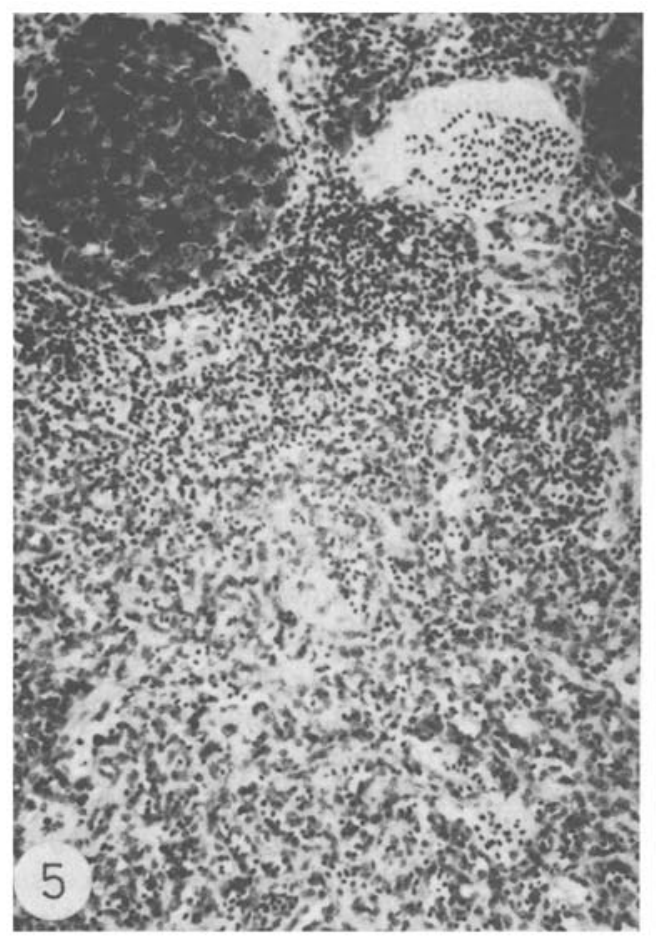

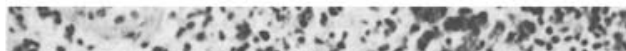

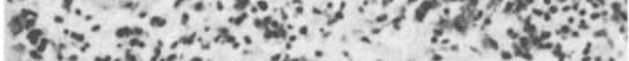

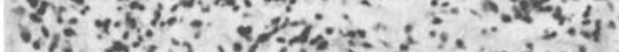
in Aw

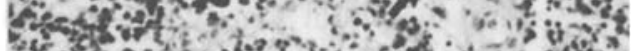
ong

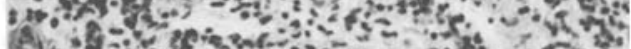

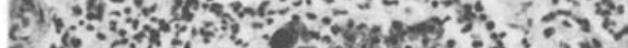

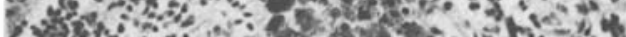

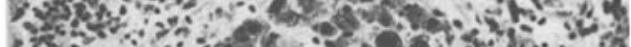

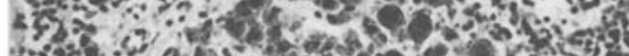

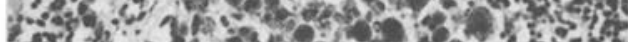

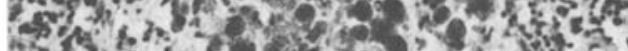
4. 30 .

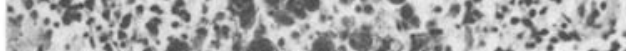

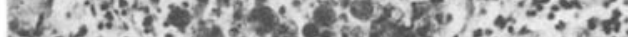

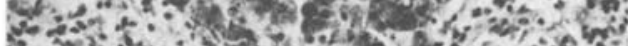

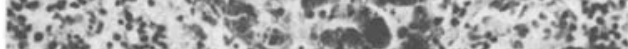

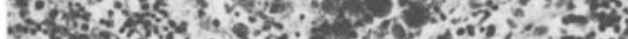

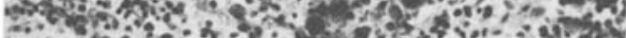

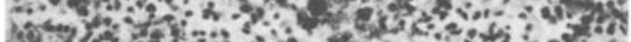

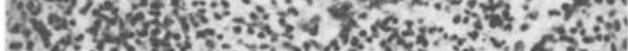

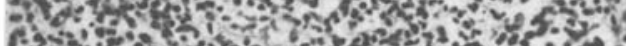

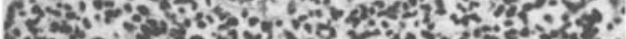

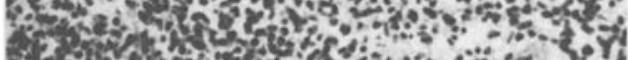

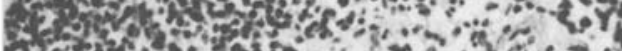
M ${ }^{2}$.

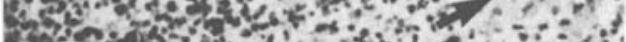
5000 a

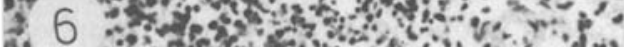

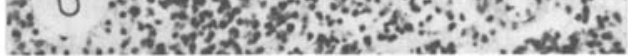
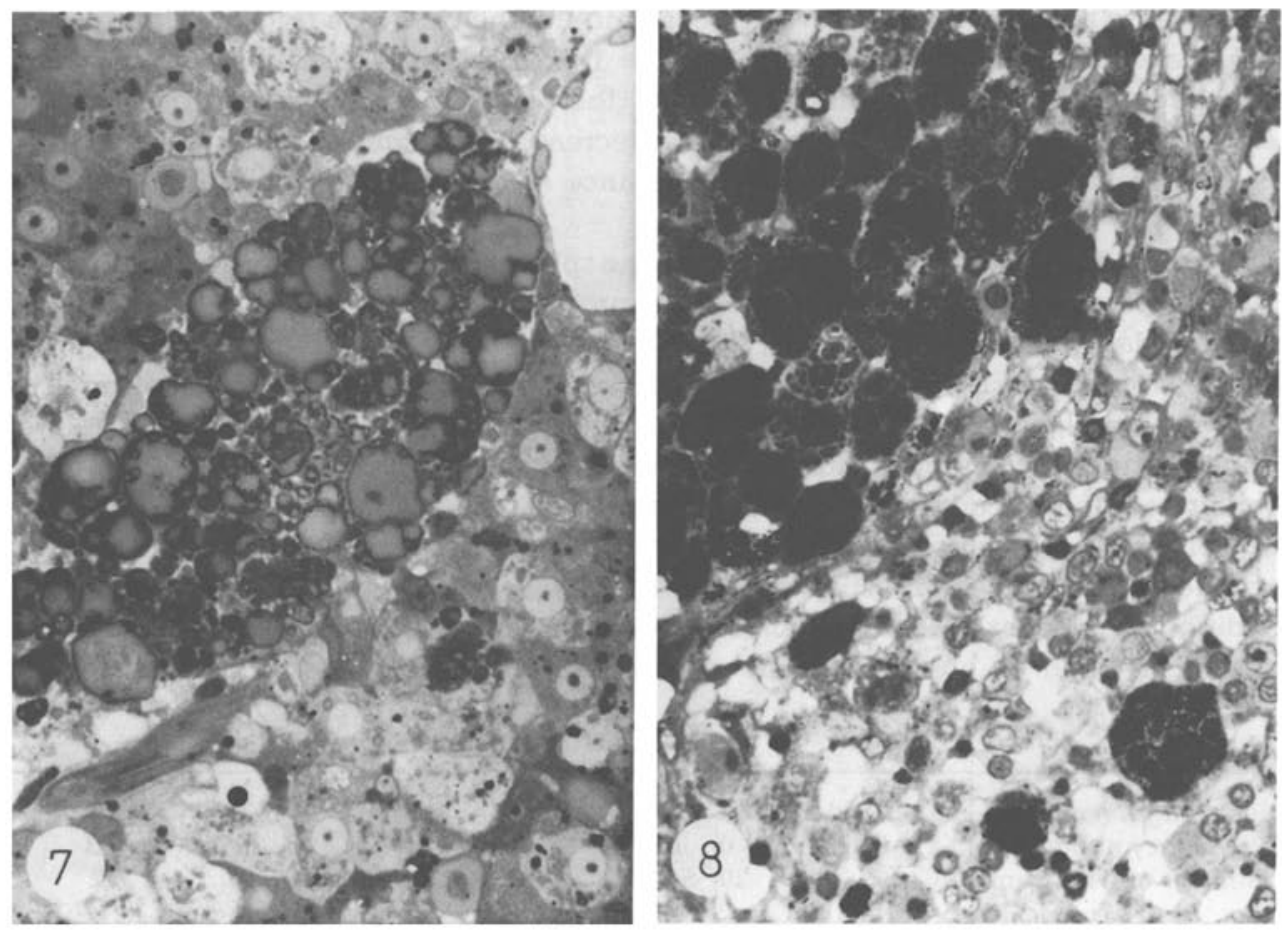
angioma, however, increased numbers of enlarged melano-macrophage centres were found (Table 1). In contrast to the liver centres, the colour of macrophages in the nodular spleen was always dark brown, and in some cases, a few inclusions contained black melanin. Thus, the structure of macrophage vacuoles was never homogeneous or vesicular, but rather coarse grained or friable (Fig. 6). The melano-macrophage centres of most of the spleens showed a strong positive reaction for ferric iron. In a few cases only, the melano-macrophage centres were surrounded by a collar of lymphocytes, but almost one third seemed to be nearly encapsulated by fibrous cells.

The following statement can be made about general differences between melanomacrophage centres in the liver and spleen of ruffe showing no obvious histopathological alterations (Table 1). Melano-macrophage centres seldom occurred in livers of small fishes between 10 and $17 \mathrm{~cm}$, but they did always occur in the spleen. Without exception, melano-macrophage centres were more abundant and larger in the spleen than in the liver of the same fish, even in cases when the liver was pathologically altered and the spleen showed no sign of a pathological reaction. The greatest percentage of the hepatic melano-macrophage centres was situated near blood vessels, whereas in the spleen, melano-macrophages aggregated within the parenchyma. The colour of macrophages was usually yellow in the liver and brown in spleen, which corresponds to their vacuolar structure: often homogeneous in the liver and always coarse-grained or friable in the spleen (Figs 7 and 8). Black melanin in the melano-macrophage centres and lymphocyte collars around them were not very abundant in either organ of the ruffe, but they were found somewhat more often in the spleen than in the liver. Furthermore, the accumulation of iron seems to be a characteristic feature of splenic melano-macrophage centres but not of those in the liver.

\section{DISCUSSION}

Melano-macrophage centres are more abundant in livers and spleens of ruffe when they are afflicted with various pathological conditions. They are also rather abundant in seemingly normal livers and spleens of ruffe from the polluted Elbe River. The functions attributed to melano-macrophage centres based mainly on studies of those in the spleen, include special immune responses (Ellis \& Sousa, 1974), bacteriocidal properties attributed to black melanin (Roberts, 1975), tissue catabolism experimentally shown during complete starvation of fishes (Agius \& Roberts, 1981), phagocytosis of foreign particles in the blood and lymph systems (Ellis et al., 1976), and storage of iron released by destruction of exhausted erythrocytes (Agius, 1979). In the spleen of ruffe from the Elbe River, black melanin seldom accumulates in the melano-macrophage centres, which are

Fig. 5. Enlarged melano-macrophage centres in the vicinity of a splenic nodule. The proliferated tissue in the lower part of photography consist of fibrous cells and erythrocytes (paraffin $5.0 \mu \mathrm{m}$; hematoxylin-eosin; $\times 195$ )

Fig. 6. Splenic melano-macrophage centre with darker vacuoles in contrast to Figure 2. Ellipsoids in this normal splenic tissue are indicated by arrows (paraffin $5.0 \mu \mathrm{m}$; hematoxylin-eosin; $\times 270$ )

Fig. 7. Hepatic melano-macrophage centre. Phagocytosed materials consist of mainly lipoid substances displaying a homogeneous structure (Epon $1.0 \mu \mathrm{m}$; toluidine blue; $\times 680$ )

Fig. 8. Border of splenic melano-macrophage centre. Inclusions of macrophages show granular to friable structures (Epon $1.0 \mu \mathrm{m}$; toluidine blue; $\times 680$ ) 
only rarely surrounded by a collar of lymphocytes. Because of these observations, it is assumed that bacteriocidal and other immunological processes are not the main functions of macrophage centres in ruffe spleen. On the other hand, most of the splenic centres stain positively for iron, which in this study was histochemically determined as haemosiderin. This leads to the conclusion that the main function of splenic melanomacrophage centres is the decomposition of blood cells.

A special relationship seems to exist between tumorous nodules of ruffe spleen and an increase in number and size of splenic melano-macrophage centres. The investigations of Ellis (1974) and Ferguson (1976) on the reticulo-endothelial system of flatfish showed that melano-macrophage centres in the spleen originate from cells of the ellipsoids. Macrophages filled with ingested substances from the blood circulation migrate from the area around the arterial capillaries to the white or red pulp of the spleen, where they form aggregates of melano-macrophages. That means that the splenic angiomas of ruffe, which consist of highly proliferated ellipsoid cells, might be a tumor consisting of precursor cells of melano-macrophages. In most tumorous spleens, melano-macrophage centres contain haemosiderin. Only those in the immediate vicinity of the nodules sometimes lack trivalent iron, even if they contain dark brown pigment. Their phagocytic activities could be directed against the tumor cells.

Melano-macrophage centres in the liver of the ruffe have different characteristics. They are generally less abundant and smaller than in the spleen, even when their number and size have been increased due to patchy pathological fat accumulation and during development of neoplastic hepatic nodules. Increased abundance of melanomacrophage centres in fish liver has been reported to be a symptom of several diseases. Elarifi (1982) studied the development of hepatic melano-macrophage centres after nematodes had infested the organ. Smith (1979) mentioned an increase of melanomacrophages in salmon suffering from lipoid liver degeneration, and Pierce et al. (1978) stated that melano-macrophage centres increased in abundance when hepatomas occurred in the livers of Parophrys vetulus.

An increase in the abundance of hepatic melano-macrophage centres has also been recorded when the water was polluted. Again Pierce et al. (1980) reported that the starry flounder (Platichthys stellatus) from the polluted Duwamish River had more hepatic melano-macrophage centres than those from unpolluted reference areas. Haensly et al. (1982) found that one long-term effect of the "Amoco Cadiz" crude oil spill was an increase in the number of melano-macrophage centres in livers of plaice from highly contaminated areas.

The differences in structure and colour of melano-macrophage centres indicate dissimilarities in their functions in spleen and liver of ruffe. As in the splenic centres, black melanin and lymphocytes are only occasionally accumulated in and around hepatic melano-macrophage centres. This is evidence against a bacteriocidal function. If hepatic centres stain positively for iron, which occurred in a minority of the organs examined, the reaction is very weak, and sometimes only single macrophages contain trace amounts of iron. Therefore, it is assumed that decomposition of blood cells is not the main function of hepatic melano-macrophage centres. Most of the macrophage centres in both diseased and normal livers are pale yellow. In many cases, the phagocytic vacuoles show a vesicular or homogeneous structure in light microscope preparations. Histochemically, they were shown to contain fatty substances. Such lipoid-filled 
macrophages do not appear only in livers which show signs of fatty degeneration in surrounding hepatocytes and many of those with tumorous growth, but also in those without any signs of pathology. Pierce et al. (1978) reported similar vacuolation to occur in melano-macrophage centres of organs with hepatocellular fat accumulation in fishes from the polluted Duwamish River. Lipoid degeneration is a histochemical response to special toxicants, and fat soluble toxicants are often demonstrated to be particularly abundant in the liver. Toxic chemicals can therefore be suspected to concentrate in the melano-macrophage centres and thus be eliminated from metabolic systems.

In 1980, Agius showed that at different phylogenetic levels, the liver and spleen change their relative importance in developing melano-macrophage centres. In the evolution from Agnatha to Chondrichthyes and on to advanced Teleostei, the liver loses and the kidney and spleen gain importance as sites of macrophage centres. This development proceeds parallel to the evolution of the lymphoid and reticulo-endothelial systems in fishes.

In this investigation, it was confirmed that the spleen is the main organ for producing melano-macrophage centres. Under conditions of pollution, followed by certain histopathological reactions, familiar immunological functions in these centres are completed in the spleen, and seem to be converted in the liver: while splenic macrophage centres are specialized for decomposition of possibly increased rates of effete blood cells, those in the liver seem to have taken on importance for storing and eventually eliminating toxic substances.

Acknowledgements. The authors wish to thank Dr. G. Peters, W. Schmidt, M. Brumm and J. Gercken for helpful assistance during preparation of ruffe. This investigation was supported by Forschungsbereich "Umweltforschung und Umweltgestaltung", Universität Hamburg.

\section{LITERATURE CITED}

Agius, C., 1979. The role of melano-macrophage centres in iron storage in normal and diseased fish - J. Fish Dis. 2, 337-343.

Agius, C., 1980. Phylogenetic development of melano-macrophage centres in fish. - J. Zool., Lond. 191, 11-31.

Agius, C. \& Roberts, R. J., 1981. Effects of starvation on the melano-macrophage centres of fish. - J. Fish Biol. 19, 161-169.

Edelstein, L. M., 1971. Melanin; A unique biopolymer. In: Pathobiology annual. Ed. by $H$. L. Ioachim. Butterworth, London, 309-324.

Elarifi, A. E., 1982. The histopathology of larval anisakid nematode infection in the liver of whiting Merlangius merlangus (L.), with some observations on blood leucocytes of the fish. $-J$. Fish Dis. $5,411-419$.

Ellis, A. E., 1974. Aspects of the lymphoid and reticulo-endothelial systems in the plaice Pleuronectes platessa L. - Ph. D. Thesis, University of Aberdeen, $255 \mathrm{pp}$.

Ellis, A. E., 1980. Antigen-trapping in the spleen and kidney of the plaice Pleuronectes platessa L. J. Fish Dis. 3, 413-426.

Ellis, A. E. \& Sousa, M. A. B. de, 1974. Phylogeny of the lymphoid system. I. A study of the fate of circulating lymphocytes in the plaice. - Eur. J. Immunol. 4, 338-343.

Ellis, A. E., Munroe, A. L. S. \& Roberts, R. J., 1976. Defence mechanisms in fish. 1. A study of the phagocytic system and the fate of intraperitoneally injected material in the plaice (Pleuronectes platessa). - J. Fish Biol. 8,67-78.

Ferguson, H. W., 1976. The relationship between ellipsoids and melano-macrophage centres in the spleen of turbot (Scophthalmus maximus) - J. comp. Path. 86, 377-380. 
Haensly, W. E., Neff, J. M., Sharp, J. R., Morris, A. C., Bedgood, M. F. \& Boem, P. D., 1982. Histopathology of Pleuronectes platessa L. from Aber Wrac'h and Aber Benoit, Brittany, France: long-term effects of the Amoco Cadiz crude oil spill. - J. Fish Dis. 5, 365-391.

Pierce, K. V., McCain, B. B. \& Wellings, S. R., 1978. The pathology of hepatomas and other liver abnormalities in English sole (Parophrys vetulus) from the Duwamish River Estuary, Seattle, Washington. - J. natn. Cancer Inst. 60, 1445.

Pierce, K. V., McCain, B. B. \& Wellings, S. R., 1980. Histopathology of abnormal livers and other organs of starry flounder Platichthys stellatus (Pallas) from the Duwamish River, Seattle, Washington, USA. - J. Fish Dis. 3, 81-91.

Roberts, R. J., 1975. Melanin-containing cells of teleost fish and their relation to disease. In: The pathology of fishes. Ed. by W. E. Ribelin \& G. Migaki. Univ. Wisconsin Press, Madison, Wisc., 399-428.

Roberts, R. J., 1978. Fish pathology, Baillière Tindall, London, $318 \mathrm{pp}$.

Romeis, B., 1948. Mikroskopische Technik. Oldenbourg, München, $695 \mathrm{pp}$.

Smith, C. E., 1979. The prevention of liver lipoid degeneration (ceroidosis) and microcytic anaemia in rainbow trout Salmo gairdneri Richardson fed rancid diets: a preliminary report. - J. Fish Dis. 2, 429-437. 